\title{
Predictive methodology of the probability ranges of total deaths from Coronavirus 19 (COVID-19) in China, Turkey, and Brazil
}

Javier Rodríguez ( $\sim$ grupoinsight2025@yahoo.es )

MD. Insight Group leader. Bogotá, Colombia.

\section{Signed Prieto}

Fis. Insight Group Research. Bogotá, Colombia.

\section{Carlos Rivera}

Ing. Institución Universitaria Politécnico Grancolombiano. Bogotá, Colombia.

Jairo Jattin

Ing. Institución Universitaria Politécnico Grancolombiano. Bogotá, Colombia.

\section{Research Article}

Keywords: public health, probability, coronavirus, pandemic

Posted Date: July 7th, 2020

DOI: https://doi.org/10.21203/rs.3.rs-40007/v1

License: (c) (i) This work is licensed under a Creative Commons Attribution 4.0 International License. Read Full License 


\section{Abstract}

Background: A country without strategies to limit the spread of a pandemic would likely result in a dramatic increase in the number of hospitalizations and deaths.

Objective: to design a methodology based on probability theory to Predict the dynamics of total deaths due to Coronavirus 19 (COVID-19) in three countries.

Methods: the total number of deaths from COVID-19 was systematized, from the day the first report was made public until April 17th, 2020 in China, Turkey, and Brazil. Eight ranges were established, which have a maximum and minimum value to correlate with the total COVID-19 deaths in each of these three countries. Next, the frequency of occurrence of each range and its probability were calculated. Subsequently, these same steps were performed, but in sub-spaces of eight consecutive days.

Results: the predictions gave probability values of 5.2E-43 for China, 4.4E-21 for Turkey and 7.9E-21 for Brazil. In orders of magnitude, China has a difference of 22 compared to the other two countries that have not reached the collapse of the health system that occurred in China. Additionally, the probability of the sub-spaces of these three countries reveals changes in the different ranges as the virus spreads.

Conclusions: the probability values allow distinctions to be made between the dynamics of deaths from COVID-19 in different countries, additionally contributing to follow-up on pandemic mitigation interventions.

\section{Introduction}

One of the four genera within the Coronaviridae family is the Betacoronavirus genus, and among these viruses, SARS-CoV, MERS-CoV and SARS-CoV-2 are found as the main exponents (Li, 2016; Lu, 2020; Paraskevis et al. 2020; Chen et al. 2020). SARS-CoV-2 was identified as a new virus whose infection was named 2019-nCoV or COVID-19 (Abd et al. 2020). The first cases of COVID-19 were reported in the city of Wuhan, in the Chinese province of Hubei (Grifoni et al. 2020). This new virus has spread rapidly from Wuhan to other areas of China and to more countries in the world (Fan et al. 2020; Wang et al. 2020; Singhal, 2020). A public health emergency was declared due to the number of positive cases and deaths by COVID-19, on January 30, 2020 and later, the World Health Organization (WHO, 2020a; 2020b) classified it as a pandemic. As of April 26th, 2020, a total of 2,804,796 confirmed total cases and 193,722 deaths from COVID-19 have been reported (WHO,2020c). Among the group of 20 countries with the highest number of cases reported by COVID-19 are China, Turkey, and Brazil. On April 17th, China increased the total number of deaths because it had not counted the people who died in their homes (WHO,2020c), while keeping quarantine and social distancing measures, among others.

To explain and predict the behavior of the current pandemic, SEIR and SIR epidemiological models are being applied. For example, the compartmentalized SEIR epidemiological model allows researchers to 
analyze the behavior of four states: susceptible to infection, exposed or latent, infected, and recovered (Grifoni et al. 2020).

Apart from these four states, this model estimates the reproductive number Ro (Fan et al. 2020;), which estimates the new infections that an infectious person will produce during infection, in a totally susceptible population in the absence of interventions (Yang et al. 2020). However, the results of the studies carried out using the SEIR and SIR models are very varied (Roda et al. 2020). One of the many causes of the variation in these results is attributed to the lack of reliable data from Wuhan before January 23 when the city was under quarantined as data confirmed in one day may have been subject to erroneous COVID-19 test results (Yang et al. 2020). In addition to this, there are studies that have shown that the estimation of Ro in the analysis of other epidemics has generated misinterpretations. Furthermore, Ro values change in different regions of the world (Ridenhour et al. 2014), therefore, this value cannot be considered to estimate the behavior of the pandemic in several countries simultaneously.

Probability was considered an empirical discipline before the end of the 19th century. For it to become a theory, it was necessary to develop proper axiomatization processes and their possible applications (Blanco, 2020; Koroliuk, 2015). In probability theory, the relationship between the frequency distribution of events and their probability is called probability distribution (Feynman et al. 1964). Among the phenomena of study of quantum mechanics is the analysis of quantum states, which have been possible to differentiate from probability distributions (Chernega et al. 2017; 2019).

Studies developed within the framework of probability theory in epidemiology have revealed the capacity of these methodologies to make annual predictions of the number of people infected by malaria and dengue in Colombia which have achieved accuracy percentages close to 100\% (Rodríguez, 2010; 2019; Rodríguez et al, 2018). Based on this line of research, the design of a new methodology based on probability theory is proposed, capable of predicting the spatial-temporal dynamics of the total number of subjects deceased by COVID-19 in China, Turkey, and Brazil. Additionally, sub-spaces of eight consecutive days were established, whose probability ranges allow to compare changes in the dynamics of the total number of deaths from COVID-19 for each of these countries.

\section{Methods}

Range (Ri): is the interval between minimum and maximum integer values of individuals deceased by COVID-19, established as follows:

$$
\begin{aligned}
& {[0-100]=1} \\
& {[100-200]=2} \\
& {[200-500]=3}
\end{aligned}
$$




$$
\begin{aligned}
& {[500-1000]=4} \\
& {[1000-5000]=5} \\
& {[5000-10.000]=6} \\
& {[10.000-20.000]=7} \\
& {[>20.000]=8}
\end{aligned}
$$

Range probability: it is the quotient between the occurrence frequency of each of the eight established rangesand the total sum of the occurrence frequencies of all the ranges, is calculated using the following equation:

$$
P\left(R_{i}\right)=\frac{\text { Frequency of appearance of the range } i}{\text { Sum of all frequencies of occurrence of all ranges }}
$$

Where $i$ takes the values of the ranges from 1 to 8 .

Probability of the dynamics of the number of infected people in a country: it is calculated with the following equation:

$$
P_{\text {dynamic }}=\prod_{i=1}^{x} P\left(R_{i}\right)
$$

Where, $x$ represents the number of days between the first report of deaths by COVID-19 for a given country and the study cut-off date.

\section{Population}

Vales for total deaths secondary to COVID-19 were taken for China from January 11, for Turkey and Brazil from March 18 to April 17th, 2020 from the WHO website (2020c). These countries were selected, as they were in the top 20 countries with the highest number of individuals deceased by COVID-19 until April 17th.

\section{Procedure}

The dates and total deaths from COVID-19 were organized in spreadsheets. Subsequently, a comparison was made between the total deaths from COVID-19 in China and the eight ranges established in the methodology (see definitions), that is, a relationship was made between the total deaths from COVID-19 with one of the eight ranges. In the same way, we proceeded with the other countries. In this way, the total 
number of deaths from COVID-19 from these countries, occupied one of these eight ranges established by the methodology (see definitions).

Next, the number of times that a certain range appeared was quantified to later evaluate the probability of the frequency of occurrence of each of them with equation 1 . This results in a probability distribution, which was evaluated by equation 2, allowing to quantify the dynamics of the total number of deaths from COVID-19 in each country.All the steps required to apply Equation 1 and 2 were performed again in a sub-space of eight consecutive days. These sub-spaces allowed analyzing the behavior of the temporal dynamics of the total number of deaths from COVID-19 in shorter fixed time intervals.

\section{Ethical Approval}

This investigation does not require an institutional ethics committee approval given that research was developed with data made publicly available where no personal or confidential information was processed.

\section{Results}

The behavior of the number of total deaths from COVID-19 for the three countries can be seen in Figure 1. The total number of deaths from COVID-19 in China, Turkey and Brazil varied between 9 to 4642, 2 to 1890 and 1 to 2141 for Brazil. China, Turkey, and Brazil occupied the first five out eight ranges that were established in this methodology (table 1). Within the five ranges occupied by the three countries, China is the country with the highest frequency of occurrence for a range, this is because, at the time of the study, China did not report more deaths due to COVID-19, clustering the cases in a single range more frequently. On the other hand, for Turkey and Brazil, the total frequency of occurrence of the first five ranges were equal, in the same way they had similar values for frequency and probability ranges, for example, range two achieved the same probability value for both countries. The behavior of the probability distribution of the frequency of appearance of each range for the three countries can be seen in Figure 2.

The probability evaluated with equation 2 for China yielded a value of 5.2E-43, while for Turkey a value of 4.4E21 was calculated and for Brazil a value of 7.9E-21 was obtained (see table 2). When comparing these three probability values, it can be seen that the difference in orders of magnitude between China, Turkey and Brazil is 22, which reveals that in orders of magnitude the dynamics of the total number of deaths from COVID-19 for April 17th were more loaded for China. On the other hand, for Turkey and Brazil, the values of probability in orders of magnitude are the same, but when observing the significant figures Brazil finds the possibility of a range change.

For the eight-day sub-spaces, the behavior of the dynamics of the total number of deaths secondary to COVID-19 for these three countries were analyzed. For China, during the first two weeks, there were no alarming changes in the number of deaths secondary to COVID -19, however, during weeks 24 and 32 , the dynamics of deaths from COVID-19, presented a considerable change in view of the fact that the dynamic went from range 3 to range 5. On the other hand, Turkey and Brazil dynamics migrated from range 1 to 
range 3 in the second week of reporting the total number of COVID-19 deaths. When comparing how the dynamics of deaths behaved in Turkey and Brazil with respect to China, it is revealed that the mortality grew more strongly in these two countries. The behavior of the dynamics of deaths from COVID-19 in these three countries can be seen in Figure 2 .

\section{Discussion}

This is the first work where a methodology founded on probability theory was developed to predict the behaviorof the dynamics of total deaths from COVID-19 in different countries. This study highlights that the lack of data was not inconvenient to make predictions, it was only necessary to observe these cases, in the context of fundamental physical and mathematical theories such as probability theory and nonrelativistic quantum mechanics. The probability ranges allow to easily compare the behavior of the dynamics of deaths in these three countries, which only after having taken the necessary mitigation measures, the cases of deaths significantly decreased China.

The methodology applied in this study was developed in the context of quantum mechanics. To establish the ranges for the eight ranges, an analogy was made between the particles that can only be at certain discrete energy levels and the number of deaths from COVID-19. Additionally, the behavior of the dynamics of deaths in these three countries was differentiated by means of the probability values, analogous to how the probability distributions can differentiate each energy level. Furthermore, the probability values of each sub-space can detect changes that are not noticeable as the pandemic spreads in each country (D'Arienzo and Coniglio, 2020).

It is worth noting that this study did not consider Ro as a starting point because it is an estimate calculated with the information that has been recorded and reported at the time of the start of a viral outbreak, as is the case SAR-CoV2. Furthermore, the variation between the estimated values for each country significantly limits forecasting the future behavior of this As mentioned, the studies developed to estimate the calculation of Ro for a given geographic area show that this parameter cannot be extrapolated to other geographical area different to the place it was calculated (Ridenhour et al. 2014). For example, in a study carried out by D'Arienzo et al. (2020), R0 was estimated using the SIR compartment method in nine cities in Italy, with the highest number of cases confirmed by COVID-19. The results of this study show that the RO value calculated in a period between $02 / 25 / 2020$ to $03 / 12 / 2020$ for these nine cities varied between 2.43 and 3.10 (D'Arienzo and Coniglio, 2020).

The line of research applied in this study also has a scientific track record in other settings of medicine as is cardiology (Rodríguez et al. 2019), Infectiology (Rodriguez et al. 2020) and molecular biology (Rodríguez et al. 2008). These methodologies demonstrate the favorability of designing methodologies based on probability theory to analyze the behavior of random or chaotic dynamics, since these approaches have made possible to predict and quantify complex phenomena, based on the study of their behavior. 


\section{Conclusion}

A methodology was developed that allows us to understand from the dynamics of total deaths from COVID-19, the impact that this has on the pandemic in different countries from a physical and mathematical context applicable to any country.

\section{Declarations}

Conflict of interest statement: The authors declare than they have no conflict of interest

\section{Acknowledgments}

We thank to Directives of Research of the Institución Universitaria Politécnico Grancolombiano, specially to Doctor David Ricciuli, Fomento a la Investigación y Creción lead and Engineer Giovanni Piedrahita, FICB-PG research group lead, for their support to our research.

\section{Funding}

Institución Universitaria Politécnico Grancolombiano

\section{References}

1. Abd El-Aziz, M., Stockand, J. D (2020) Recent progress and challenges in drug development against COVID-19 coronavirus (SARS-CoV-2) - an update on the status. Infection, genetics and evolution :journal of molecular epidemiology and evolutionary genetics in infectious diseases, 83, 104327. Advance online publication. https://doi.org/10.1016/j.meegid.2020.104327

2. Blanco L. (2010) Probabilidad. Bogotá: Universidad Nacional de

3. Chen L, Liu W, Zhang Q, Xu K, Ye G, Wu W, Sun Z, Liu F, Wu K, Zhong B, Mei Y, Zhang W, Chen Y, Li Y, Shi M, Lan K, Liu Y (2020) RNA based mNGS approach identifies a novel human coronavirus from two individual pneumonia cases in 2019 Wuhan Emerging microbes \& infections, 9(1), 313-319. https://doi.org/10.1080/22221751.2020.1725399

4. Chernega V, Man'ko O, Man'ko V. (2017) Probability Representation of Quantum Observables and Quantum States. Journal of Russian Laser Research. 38(4):324-333. DOI: 1007/s10946-017-9648-2

5. Chernega VN, Man'ko OV, Man'ko VI (2019) Probability Representation of Quantum States as a Renaissance of Hidden Variables-God Plays Coins. J Russ Laser ～40(2):107-1020. https://doi.org/10.1007/s10946-019-09778-4

6. D'Arienzo M, Coniglio A (2020) Assessment of the SARS-CoV-2 basic reproduction number, R0, based on the early phase of COVID-19 outbreak in Italy [published online ahead of print, $2020 \mathrm{Apr} 2$ ]. doi:10.1016/j.bsheal.2020.03.004 
7. Fan C, Liu L, Guo W, Yang A, Ye C, Jilili M, Ren M, Xu P, Long H, Wang Y Prediction of Epidemic Spread of the 2019 Novel Coronavirus Driven by Spring Festival Transportation in China: A Population-Based International journal of environmental research and public health, 17(5), 1679 https://doi.org/10.3390/ijerph17051679

8. Feynman RP, Leighton RB, Sands (1964) Probabilidad. En: Feynman RP, Leighton RB, Sands M. Física. Vol. 1. Wilmington: Addison-Wesley Iberoamericana, S. A. p. 6-1, 6-16.

9. Grifoni A, Sidney J, Zhang Y, Scheuermann R, Peters B, Sette A (2020) A Sequence Homology and Bioinformatic Approach Can Predict Candidate Targets for Immune Responses to SARS-CoV-2. Cell host \& microbe, 27(4), 671-680.e2. https://doi.org/10.1016/j.chom.2020.03.002

10. Koroliuk B.V (2015) Gnedenko: Classic of Limit Theorems in the Theory of Probability. Methodol Comput Appl Probab. 17: 5-14.

11. Li F (2016) Structure, Function, and Evolution of Coronavirus Spike Annual review of virology, 3(1), 237-261. https://doi.org/10.1146/annurev-virology-110615-042301.

12. Lu R, Zhao X, Li J, Niu P, Yang B, Wu H, Wang W, Song H, Huang B, Zhu N, Bi Y, Ma X, Zhan F, Wang L,

13. Hu T, Zhou H, Hu Z, Zhou W, Zhao L, Chen J, ... Tan W (2020) Genomic characterisation and epidemiology of 2019 novel coronavirus: implications for virus origins and receptor Lancet (London, England), 395(10224), 565-574. https://doi.org/10.1016/S0140-6736(20)30251-8

14. Paraskevis D, Kostaki E, Magiorkinis G, Panayiotakopoulos G, Sourvinos G, Tsiodras S. (2020) Fullgenome evolutionary analysis of the novel corona virus (2019-nCoV) rejects the hypothesis of emergence as a result of a recent recombination event. Infection, genetics and evolution: journal of molecular epidemiology and gevelics in infectious 79, https://doi.org/10.1016/j.meegid.2020.104212

15. Ridenhour B, Kowalik J, Shay K (2014) Unraveling R0: considerations for public health applications. American journal of public health, 104(2), e32-e41. https://doi.org/10.2105/AJPH.2013.301704

16. Roda W, Varughese B., Han D, Li M. Y (2020) Why is it difficult to accurately predict the COVID19epidemic?. Infectious Disease Modelling, 5, 271-281. https://doi.org/10.1016/j.idm.2020.03.001

17. Rodríguez J (2010) Método para la predicción de la dinámica temporal de la malaria en los municipios de Colombia. Rev Panam Salud Pública 27(3):211-8.

18. Rodríguez J (2010) Method for predicting the temporal dynamics of malaria in the municipalities of Rev. Panam. Public Health 27, 211-218. DOI: 10.1590/s1020-49892010000300008

19. Rodríguez J (2019) Spatio-temporal probabilistic prediction of appearance and duration of malaria outbreak in municipalities of Colombia. Journal of Physics: Conf. Series 1160,012018. Doi:10.1088/1742-6596/1160/1/012018

20. Rodríguez J, Prieto S, Pérez C, Correa C, Mendoza F, Bravo J, Morales C, Rojas N, Flórez M (2018)

21. Probabilistic space-time prediction of the total and severe dengue epidemic in Colombia. Rev. Public Health 20,352-358. Doi: 10.15446 / V20n3.42701. 
22. Rodríguez J, Prieto S, Pérez C, Correa C, Soracipa Y, Jattin J, David A (2020) Predicción temporal de CD4+en 80 pacientes con manejo antirretroviral a partir de valores de leucocitos. Infectio 24,103-107. DOI: http://dx.doi.org/10.22354/in.v24i2.841

23. Rodríguez J (2008) Binding to Class II HLA Theory: Probability, Combinatory and Entropy Applied to Peptide Sequences. Inmunología 27,151-166. DOI:10.1016/S0213-9626(08)70064-7

24. Rodríguez J, Prieto S, Ramírez L (2019) A novel heart rate attractor for the prediction of cardiovascular Informatics in Medicine Unlocked 15,100174. https://doi.org/10.1016/j.imu.2019.100174

25. Singhal (2020) A Review of Coronavirus Disease-2019 (COVID-19). Indian J Pediatr. 87(4):281-286. doi:10.1007/s12098-020-03263-6

26. Wang C, Horby W, Hayden F.G, Gao G. F (2020) A novel coronavirus outbreak of global health concern. Lancet (London, England), 395(10223), 470-473. https://doi.org/10.1016/S01406736(20)30185-9

27. World Health First meeting of Emergency Committee regarding the novel coronavirus outbreak. 2020a [updated 2020 April 13]. Available from: https://www.who.int/emergencies/diseases/novelcoronavirus-2019/events-as-they-happen

28. World Health Coronavirus disease (COVID-19) outbreak. 2020b [updated 2020 April 13]. Available from: https://www.who.int/westernpacific/emergencies/covid-19

29. World Health Organization. Coronavirus (COVID-19). 2020c [updated 2020 April 17]. Available from: https://covid19.who.int/

30. Yang Z, Zeng Z, Wang K, Wong S, Liang W, Zanin M, Liu P, Cao X, Gao Z, Mai Z, Liang J, Liu X, Li S, Li Y, Ye F, Guan W, Yang Y, Li F, Luo S, Xie Y, ... He J (2020) Modified SEIR and Al prediction of the epidemics trend of COVID-19 in China under public health Journal of thoracic disease, 12(3), 165174. https://doi.org/10.21037/jtd.2020.02.64

\section{Tables}

Due to technical limitations, Tables 1-3 are provided in the Supplementary Files section.

\section{Figures}




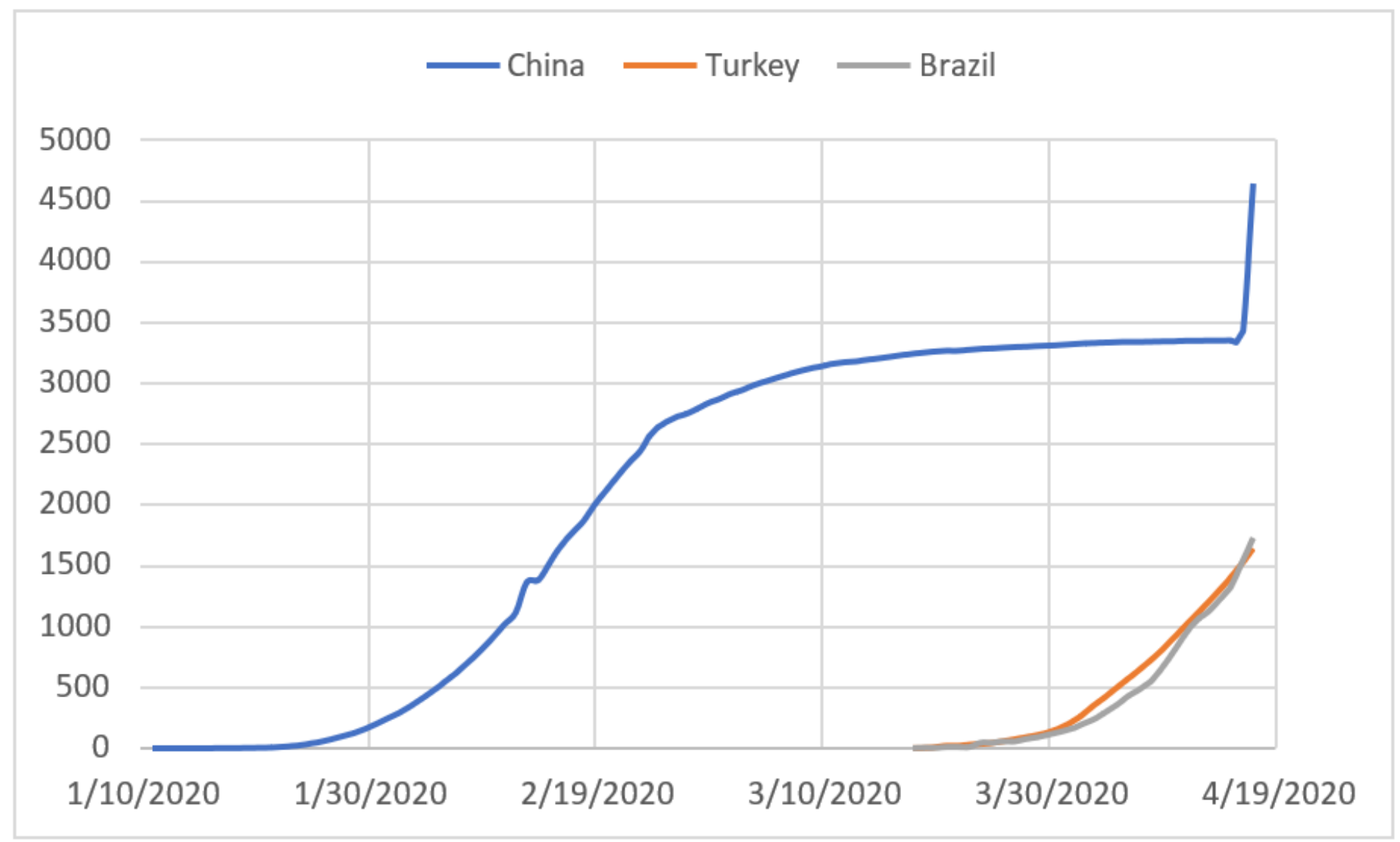

\section{Figure 1}

Dynamics of the number of total deaths secondary to COVID-19 reported in China, Turkey, and Brazil. 


$$
\diamond \text { China }-\square-\text { Turkey } \Delta \text { Brazil }
$$

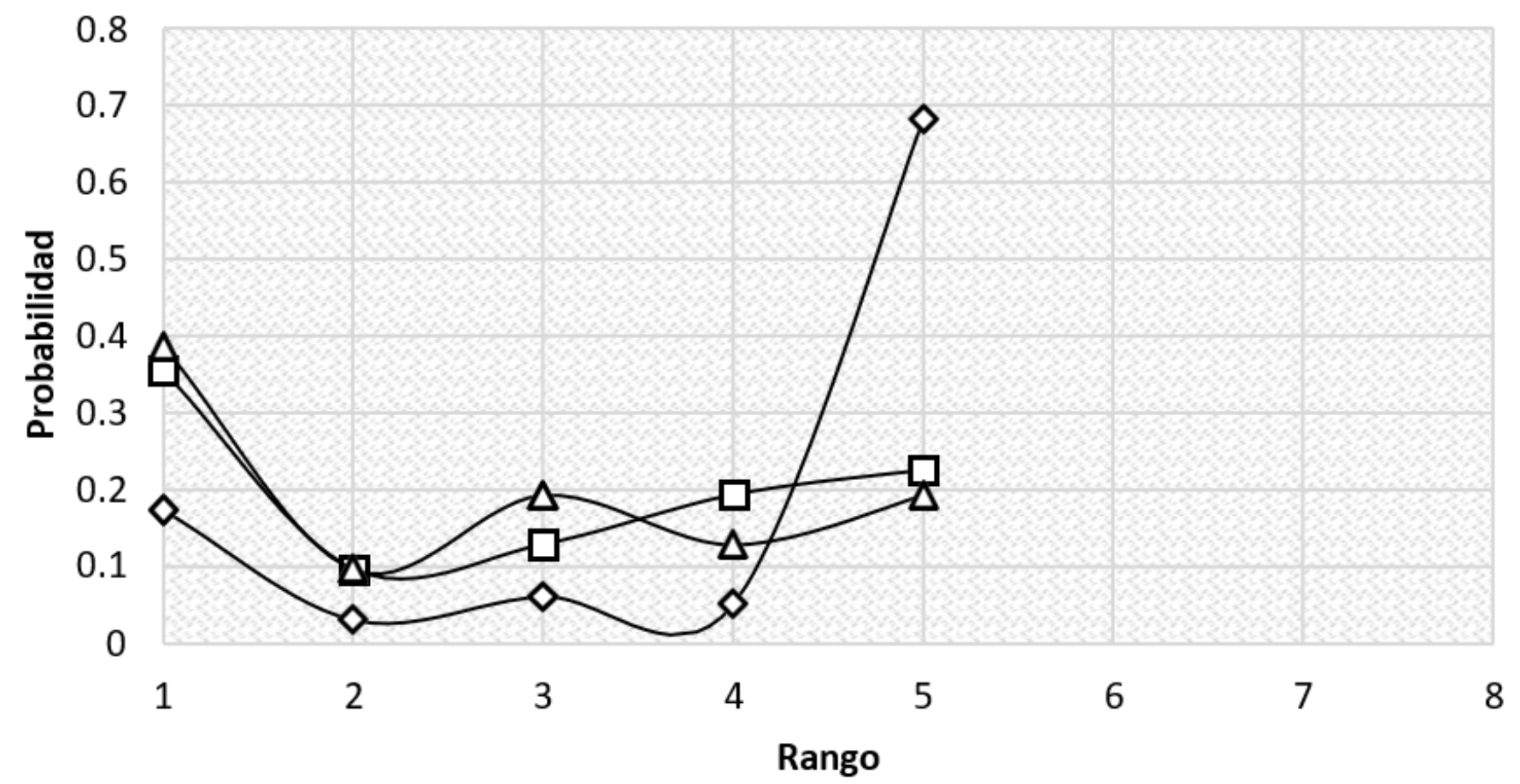

Figure 2

Probability distributions of the ranges of China, Turkey and Brazil taken from Table 1.

\section{Supplementary Files}

This is a list of supplementary files associated with this preprint. Click to download.

- Tables.docx 